\title{
Biological and cognitive underpinnings of religious fundamentalism
}

Wanting Zhong ${ }^{\mathrm{a}, \mathrm{b} 1}$, Irene Cristofori ${ }^{\mathrm{a}, \mathrm{b} 1}$, Joseph Bulbulia ${ }^{\mathrm{c}}$, Frank Krueger, ${ }^{\mathrm{d}, \mathrm{e}}$, Jordan Grafman ${ }^{\mathrm{a}, \mathrm{b}, \mathrm{f}}$

${ }^{a}$ Cognitive Neuroscience Laboratory, Brain Injury Research, Shirley Ryan AbilityLab, Chicago, IL 60611, USA

${ }^{\mathrm{b}}$ Department of Physical Medicine and Rehabilitation, Feinberg School of Medicine, Northwestern University, Chicago, IL 60611, USA

${ }^{c}$ School of Art History, Classics and Religious Studies, Victoria University of New Zealand, Wellington 6140, New Zealand

${ }^{\mathrm{d}}$ Molecular Neuroscience Department, George Mason University, Fairfax, VA 22030, USA ${ }^{\mathrm{e}}$ Department of Psychology, George Mason University, Fairfax, VA 22030, USA

fDepartments of Neurology, Psychiatry, and Cognitive Neurology \& Alzheimer's Disease, Feinberg School of Medicine, Department of Psychology, Northwestern University, Chicago, IL 60611, USA

*Corresponding author: Jordan Grafman, PhD, Cognitive Neuroscience Laboratory, Brain Injury Research Program, Shirley Ryan AbilityLab, 345 E Superior Street, Suite 1796, 60611 Chicago, USA. Office: 312-238-1495 Fax: 312-238-2208. jgrafman@northwestern.edu

\begin{abstract}
Beliefs profoundly affect people's lives, but their cognitive and neural pathways are poorly understood. Although previous research has identified the ventromedial prefrontal cortex (vmPFC) as critical to representing religious beliefs, the means by which vmPFC enables religious belief is uncertain. We hypothesized that the vmPFC represents diverse religious beliefs and that a vmPFC lesion would be associated with religious fundamentalism, or the narrowing of
\end{abstract}

\footnotetext{
${ }^{1}$ These authors contributed equally to the manuscript.
} 
religious beliefs. To test this prediction, we assessed religious adherence with a widely-used religious fundamentalism scale in a large sample of 119 patients with penetrating traumatic brain injury (pTBI). If the vmPFC is crucial to modulating diverse personal religious beliefs, we predicted that pTBI patients with lesions to the vmPFC would exhibit greater fundamentalism, and that this would be modulated by cognitive flexibility and trait openness. Instead, we found that participants with dorsolateral prefrontal cortex (dlPFC) lesions have fundamentalist beliefs similar to patients with vmPFC lesions and that the effect of a dlPFC lesion on fundamentalism was significantly mediated by decreased cognitive flexibility and openness. These findings indicate that cognitive flexibility and openness are necessary for flexible and adaptive religious commitment, and that such diversity of religious thought is dependent on dlPFC functionality.

Keywords: Traumatic brain injury, prefrontal cortex, religious beliefs, fundamentalism

\section{Introduction}

\subsection{Religious Fundamentalism}

Religious beliefs are socially transmitted mental representations that may include supernatural or supernormal episodes that are assumed to be real. Religious beliefs, like other beliefs, are embedded in different ways in different people and societies (Cristofori \& Grafman, in press).

One form of religious belief, religious fundamentalism, embodies adherence to a set of firm religious beliefs advocating unassailable truths about human existence (Altemeyer \& 
Hunsberger, 1992). According to the Baylor Religion Survey, a national survey study conducted with a nationally representative sample of 1721 respondents from the United States, $7.7 \%$ of all respondents reported being "Fundamentalist" as a part of their religious identity; $1.0 \%$ agreed that "Fundamentalist" was the one term that best described their religious identity (Bader, et al., 2006).

Evolutionary psychology explains the appeal of religious fundamentalism in terms of social functional behavior, since it promotes coherence and predictability among individuals within religious groups (Kay, Gaucher, Napier, Callan, \& Laurin, 2008; McCullough \& Willoughby, 2009). Fundamentalism requires a departure from ordinary empirical inquiry: it reflects a rigid cognitive strategy that fixes beliefs and amplifies within-group commitment and out-group bias (Altemeyer \& Hunsberger, 2005). Recent studies have linked religious fundamentalism to violence (Ginges, Hansen, \& Norenzayan, 2009), denial of scientific progress (Scheufele, Corley, Shih, Dalrymple, \& Ho, 2009), and reinforced its role in prejudice towards out-groups (Hunsberger \& Jackson, 2005).

Fundamentalism is characterized by a rigidity and inflexibility in one's beliefs. Such beliefs are not damaging — as we might expect from beliefs that do not update in response to their natural and social environments. The neurological systems that enable such inflexible, non-disastrous beliefs remain poorly understood. Importantly, it has long been understood that not all religious people are closed to developing their faith (Batson \& Schoenrade, 1991a, 1991b). On the other hand, beliefs about the existence of spirituality realities tend to be closer on the spectrum to ideology than they are to mundane updatable empirical beliefs (Bulbulia \& Sosis, 2009a). Here we consider religious fundamentalism - as an extreme form of spiritual beliefs — to better understand the mechanisms that give rise to non-pathological, non-Bayesian beliefs. 


\subsection{The Prefrontal Cortex and Social Beliefs}

Our study explores whether fundamentalism is modulated by the prefrontal cortex (PFC), an important brain area involved in social event knowledge, abstractions and higher order social belief systems. Substantial evidence indicates that damage to the PFC can modify individuals' belief systems (Forbes \& Grafman, 2010; Krueger \& Grafman, 2012). For instance, patients with ventromedial prefrontal cortex (vmPFC) lesions rated radical political statements as more moderate than matched controls (Cristofori, Viola, et al., 2015) and focal damage to the vmPFC resulted in greater religious fundamentalism, compared to healthy controls (Asp, Ramchandran, $\&$ Tranel, 2012). Thus, although a collection of cortical sectors function together to help shape and formulate beliefs, the PFC may be a critical hub for the representation of the diverse and abstract social beliefs that lie at the core of many religions.

In general, religious beliefs tend to differ from empirical beliefs. Although people may think subjectively of religious belief as a true or false representation of how the world is, it is notable that certain religious beliefs do not generally update in response to evidence, and that conservatism is especially notable in the case of fundamentalist beliefs. Empirical beliefs are indications of how the world appears to us and are updated according to accumulated evidence. Fundamentalist religious beliefs, in comparison, do not track and predict variation in the world. Rather, they appear to track, and predict, social group-level commitments (Bulbulia \& Schjoedt, 2012). For this reason, it has been hypothesized that religious beliefs encourage cooperative exchange (Bulbulia \& Sosis, 2009b). This social-functionalist account also predicts that religious commitments are affected by the capacity for cognitive flexibility. To test this prediction, we hypothesized that impaired cognitive flexibility would result in greater religious resolve, which we operationalized using previously validated religious fundamentalism scales. 


\subsection{Cognitive Flexibility, Openness and Religiosity}

Cognitive flexibility across a broad spectrum of lineages, including humans, evolved for ecological prediction and control. It allows organisms to update beliefs in light of evidence. In humans, cognitive flexibility enables efficient task switching, and is linked with inhibition and working memory (Canas, Quesada, Antoli, \& Fajardo, 2003). It is mostly studied using paradigms that involve switching between different tasks (Monsell, 2003), which require the ability to disengage attention and resolve interference from a previous task, and to update new stimulus and task information (Mayr \& Keele, 2000). The execution of such paradigms, which is a manifestation of cognitive flexibility, involves a distributed subcortical and cortical neural network (Alvarez \& Emory, 2006), including the PFC and basal ganglia (Kim, Johnson, Cilles, \& Gold, 2011; Monchi, Petrides, Strafella, Worsley, \& Doyon, 2006). Further studies have indicated that distinct subregions of the PFC play specific roles in cognitive flexibility. For example, the dorsolateral prefrontal cortex (dlPFC) has been robustly associated with the formation of distractor-resistant memories (Toepper, et al., 2010) and with switching between sets of rules (Ravizza \& Carter, 2008).

Individuals with traumatic brain injury (TBI) often suffer impairments in cognitive flexibility as a result of damage to areas controlling executive processes, such as the PFC (Whiting, Deane, Simpson, McLeod, \& Ciarrochi, 2015), resulting in task-switching deficits and excessive perseverance in their behavior. In a recent study, Barbey, Colom, and Grafman (2013) found that cognitive flexibility critically relies on the PFC based on a study of individuals with penetrating (p) TBI. 
Personality traits have been associated with aspects of cognition, the PFC, and religious beliefs. For example, openness, which refers to a range of personality tendencies including curiosity, appreciation for complexity, creativity, and non-traditional values (Connelly, Ones, Davies, \& Birkland, 2014), influences both personal experience and social interactions (McCrae, 1996). Openness has a moderate relation to general cognitive functioning (Chapman, et al., 2012; DeYoung, et al., 2011; von Stumm, 2013), and it is associated with verbal and crystallized intelligence (Schretlen, van der Hulst, Pearlson, \& Gordon, 2010). Of relevance to our research, some studies have found that openness plays a role in political and religious beliefs. Openness accounts for significant variance in political self-efficacy beliefs, which in turn accounted for political participation (Vecchione \& Caprara, 2009). Strikingly, higher level of openness - often assumed to lead to less religiosity - leads to increased religious mindfulness, religious support, and spirituality (Lewis, Ritchie, \& Bates, 2011).

Openness has been hypothesized to depend on the dlPFC and dopaminergic projections into the frontal cortex (DeYoung, et al., 2011; DeYoung, Peterson, \& Higgins, 2005). In support of this hypothesis, a recent fMRI study has found that openness was associated with increased functional connectivity in the midbrain-prefrontal dopaminergic circuit (ventral tegmental area/substantia nigra and dlPFC) (Passamonti, et al., 2015). Other resting state fMRI studies found that openness was associated with functional connectivity between the anterior cingulate and precuneus, and areas in the midline default mode network and dlPFC (Adelstein, et al., 2011); and that openness was associated with spontaneous low frequency oscillations in the thalamus, amygdala, and superior frontal gyrus (Kunisato, et al., 2011).

As implied earlier in the introduction, previous research indicates that certain forms of religiosity are associated with a preference for certainty and avoidance of uncertainty (Jost, Glaser, 
Kruglanski, \& Sulloway, 2003). In particular, fundamentalism is associated with the need for cognitive closure (Brandt \& Reyna, 2010; Saroglou, 2002), which mediates the relationship between fundamentalism and prejudice towards value-violating outgroups, with closemindedness and preference for order and predictability accounting for the effect (Brandt \& Reyna, 2010). A need for cognitive closure represents the desire for predictability and rigidity instead of openness, and is correlated with conservative, conforming values (Calogero, Bardi, \& Sutton, 2009; Kruglanski \& Webster, 1996). Recently, a number of studies have found an inverse relationship between analytic thinking and religious disbelief (Gervais \& Norenzayan, 2012; Norenzayan, Gervais, \& Trzesniewski, 2012; Willard \& Norenzayan, 2013). These studies describe analytic thinking as an underminer of religious beliefs which may either suppress default tendencies to form religious beliefs or inhibit culturally acquired concepts. Finally, it has been argued that religious beliefs arise from deficits in perceptual tracking of ecological variation (e.g. Foster \& Kokko, 2009; Guthrie, 1993). Collectively, these findings predict that fundamentalism may be related to reduced cognitive flexibility and trait openness, and that these cognitive strategies critically rely on processing in the PFC.

\subsection{Current study aims}

Although previous research has identified the vmPFC as critical to representing religious beliefs, the means by which vmPFC enables such beliefs remain scarcely examined. To study the biological and cognitive basis of fundamentalism, we tested a sample of male Vietnam combat veterans with focal pTBI and administered the Religious Fundamentalism Scale (RFS; Altemeyer \& Hunsberger, 1992), a valid, standardized psychometric measure of religious fundamentalism. This specific cohort of Vietnam combat veterans with pTBI is unique given its large size and the availability of an extensive clinical and experimental data set as well as a pre- 
injury intelligence measure. Since fundamentalism entails a firm adherence to a set of beliefs and a desire for cognitive closure, cognitive flexibility and openness present a challenge for fundamentalist thinking. Thus, we hypothesized that lesions to the vmPFC would be associated with increased fundamentalism, and this relationship would be mediated by cognitive flexibility and trait openness. Given the critical role of the dlPFC in modulating openness and cognitive flexibility, we also hypothesized that a dIPFC lesion should indirectly influence fundamentalism, through its effect on cognitive flexibility and openness.

\section{Materials and methods}

\subsection{Participants}

Participants were male combat veterans recruited from the W.F. Caveness Vietnam Head Injury Study Registry (VHIS) during Phase 4 (40 years after the injury), conducted between 2009 and 2012 at the National Institute of Neurological Disorders and Stroke (NINDS) in Bethesda, MD (Raymont, Salazar, Krueger, \& Grafman, 2011). Given its relatively large sample size and wealth of pre- and post-injury data, the VHIS provides a unique opportunity to investigate brainbehavior relationships using lesion mapping methods. Our sample consisted of 119 veterans with pTBI and 30 healthy controls (HC), who also served in combat in Vietnam but had no history of brain-injury; all participants completed the Religious Fundamentalism Scale (Table 1). 
Participants also responded to a question about their religious affiliation. The pTBI group consisted of $2.5 \%$ Mormons, $38.8 \%$ Protestant, $16.3 \%$ Roman Catholic, $10 \%$ had other affiliation, and $32.5 \%$ did not respond to this question. The HC group consisted of $35.3 \%$ Protestant, 23.5\% Roman Catholic, and 41.2\% did not respond to this question.

Ethics. The Institutional Review Board at the National Institutes of Health in Bethesda (MD) approved all study procedures and all participants provided written consent.

\subsection{Neuropsychological testing}

During Phase 4 evaluation of the VHIS, participants underwent extensive neuropsychological testing over a period of 5 days at the NINDS. We report a subset of these neuropsychological measures for control and descriptive purposes, including the Armed Forces Qualification Test (AFQT-7A, 1960) for general intelligence both before and after injury and the Token Test (TT; McNeil \& Prescott, 1994), for verbal comprehension.

Religious fundamentalism was measured using a shortened, balanced 10-item version of the Religious Fundamentalism Scale (RFS; Altemeyer \& Hunsberger, 1992). The RFS is a validated, standardized psychometric measure widely used to study religious fundamentalist beliefs. The RFS defined religious fundamentalism as a cognitive construct based on specific religious beliefs: existence of religious teachings containing the fundamental truth about humanity; this fundamental truth is opposed to evil; the fundamental truth must be followed daily, and people that follow this fundamental truth have a special relationship with God. The fundamentalism scale included statements such as: "To lead the best, most meaningful life, one must belong to the one, true religion"; "It is more important to be a good person than to believe in God and the right religion." Following the methodology employed by (Duckitt, 2001), five con-trait and five 
pro-trait items were randomly selected from the full 20-item scale (see Sibley, Robertson, \& Wilson, 2006). Participants responded to the statements on a 9-point Likert Scale (from Strongly Disagree to Strongly Agree). A metric indicating degree of fundamentalism was generated by performing a factor analysis on the ten RFS items and calculating a factor score for each participant using the regression method, standardized to a mean of zero and standard deviation of 1. Participants also responded to questions about their religious involvement (Supplementary Methods).

Cognitive flexibility was assessed by the Delis-Kaplan Executive Function System (D-KEFS; Delis, Kaplan, \& Kramer, 2001) sorting test. The sorting test is composed of two tasks, free sorting and sort recognition. Mixed cards with both various perceptual features and printed words are used in the tasks. In the free sorting task, the participant is asked to sort the cards into two groups according to as many categorization rules as possible, and to describe the rules used to generate each sort. In the sort recognition task, the examiner sorts the cards into two groups according to different rules, and the participant is asked to identify the categorization rule used to produce each sort. The combined free sort and sort recognition score, which sums correct description scores in the two tasks, is calculated to measure performance in the sorting test.

The revised NEO Personality Inventory (NEO-PI-R; Costa \& McCrae, 1992) measures 5 core personality dimensions: Extraversion, Neuroticism, Openness, Agreeableness, and Conscientiousness. We selected the Openness dimension as our openness measure.

\subsection{CT acquisition}

Computed Tomography (CT) scans were obtained and lesion volume and location were determined as described in Supplementary Methods. We calculated brain volume loss across the 
entire brain and within regions of interest defined using the automated anatomical labeling (AAL) atlas (Tzourio-Mazoyer, et al., 2002).

\subsection{Group analysis}

To test hypothesized links between specific brain areas in the PFC and fundamentalism, we selected patients with focal lesions predominantly to the vmPFC, dlPFC or outside these regions, as well as healthy controls, and compared the fundamentalism ratings across these groups (vmPFC group: $\mathrm{N}=24$; dlPFC group: $\mathrm{N}=31$; no PFC group: $\mathrm{N}=37$; $\mathrm{HC}$ group: $\mathrm{N}=30$; see Fig. 1).

We determined lesion size as the percentage of structure damaged by a lesion in specified regions of interest (ROIs). The vmPFC and dlPFC ROIs were defined based on AAL structures within a range of MNI coordinates (see Gozzi, Raymont, Solomon, Koenigs, \& Grafman, 2009; Krueger, et al., 2011). The vmPFC ROI included portions of the following AAL structures, bounded by the MNI coordinates $\mathrm{z} \leq 1,-20 \leq \mathrm{x}<0$ (left hemisphere), $0 \leq \mathrm{x} \leq 20$ (right hemisphere): superior frontal gyrus (orbital), superior frontal gyrus (medial), middle frontal gyrus (orbital), inferior frontal gyrus (orbital), olfactory cortex, gyrus rectus, anterior cingulate and paracingulate gyri. The dlPFC ROI included portions of the following AAL structures, bounded by the MNI coordinates $\mathrm{z}>1, \mathrm{x}<-10$ (left hemisphere), $\mathrm{x}>10$ (right hemisphere): superior frontal gyrus (dorsolateral), middle frontal gyrus (lateral), and inferior frontal gyrus (pars triangular).

A patient was included in the vmPFC group if the percentage of lesion in the vmPFC was larger than the percentage of lesion in the dlPFC. Similarly, a patient was included in the dlPFC group if the percentage of lesion in the dlPFC was larger than the percentage of lesion in the vmPFC 
(for a similar procedure, see Gozzi, et al., 2009). Patients with large temporal or parietal lesions in addition to PFC damage were excluded from the vmPFC and dlPFC groups. Among the 24 patients with predominantly vmPFC lesions, only 2 had lesions isolated to the vmPFC. Among the 31 patients with predominantly dlPFC lesions, 19 had lesions isolated to the dlPFC. Thus, these numbers were insufficient to perform a subgroup analysis on lesions only affecting either vmPFC or dlPFC.

\subsection{Mediation analysis}

To test the hypothesis that the effect of frontal lesions on fundamentalism is mediated by cognitive flexibility or openness, we performed mediation analyses in all pTBI patients. We used the D-KEFS Sorting test (Combined Free Sort \& Sort Recognition score) as a measure of cognitive flexibility of thinking, and the NEO Openness scale as a measure of openness. We entered vmPFC or dlPFC lesion size as the independent variable, D-KEFS sorting test score or Openness scale as the mediating variable, and fundamentalism score as the dependent variable, while statistically controlling for lesion size in the neighboring PFC region (e.g. controlling for dlPFC lesion when vmPFC lesion is the predictor, or controlling for vmPFC lesion when dlPFC is the predictor). We used the PROCESS macro (Hayes, 2013) implemented in SPSS 21 to estimate the mediation model, using a boot-strapping approach (5000 iterations) to evaluate the bias-corrected $95 \%$ confidence intervals of the size of the indirect effect.

\subsection{Statistical analysis}

We performed all behavioral analysis with SPSS 21.0 (Armonk, NY: IBM Corp.), with significance level set to 0.05 (two-tailed) for all analysis. We examined the normality of data using the Kolmogorov-Smirnov test, and parametric tests were conducted on normally 
distributed data. We computed Pearson's correlation coefficient to assess the relationship between cognitive flexibility, openness and fundamentalism in pTBI patients and HC. We compared fundamentalism scores across the lesion groups with one-way ANOVA and conducted post-hoc tests with Bonferroni correction.

\section{Results}

\subsection{Fundamentalism scale score}

The religious fundamentalism scores are reported in Table 1 for the different groups. Religious fundamentalism was statistically significantly correlated with religious involvement (see Supplementary Results).

In HCs, we did not observe a correlation between fundamentalism score and cognitive flexibility $(\mathrm{r}=-0.07, \mathrm{p}=0.74)$. There was a negative association between openness and fundamentalism in $\mathrm{HC}(\mathrm{r}=-0.44, \mathrm{p}=0.014)$, suggesting that higher fundamentalist beliefs are associated with less openness.

In pTBI patients, fundamentalism was negatively correlated with both cognitive flexibility $(r=-$ $0.31, \mathrm{p}=0.001)$ and openness $(\mathrm{r}=-0.37, \mathrm{p}<0.001)$, indicating that higher fundamentalist beliefs 
are associated with diminished cognitive flexibility as well as less openness in brain-injured patients.

\subsection{Lesion group analysis}

To test the influence of lesions to PFC regions on fundamentalist beliefs, we compared the fundamentalism scores among patients with focal lesions in the vmPFC or dlPFC, patients with lesions sparing vmPFC and dlPFC, and healthy controls (Fig. 2). One-way ANOVA revealed a statistically significant difference in fundamentalism across these groups $\left[\mathrm{F}_{(3,118)}=3.00, \mathrm{p}=\right.$ 0.033, $\left.\eta^{2}=0.07\right]$. Post-hoc pairwise comparison after Bonferroni correction showed that the vmPFC lesion group $(\mathrm{M}=0.46, \mathrm{SD}=0.90)$ had a higher fundamentalism score than the no PFC lesion group $(\mathrm{M}=-0.23, \mathrm{SD}=1.01, \mathrm{p}=0.044$, Cohen's $\mathrm{d}=0.71)$. Bonferroni corrected pairwise comparison showed that there was no statistically significant difference in fundamentalism scores between the vmPFC group and the dlPFC group $(p=1)$ or the HC group $(p=0.12)$. There was no statistically significant difference observed in fundamentalism scores between the dlPFC group and any of the other groups ( $\mathrm{p}>0.7$ for all adjusted pairwise t-tests).

Since intelligence is associated with religiosity (Zuckerman, Silberman, \& Hall, 2013), we compared pre-injury and post-injury intelligence scores among the selective groups. A KruskalWallis Test comparing the pre-injury AFQT scores showed that there was no statistically significant difference among the selective groups $\left(\chi^{2}=5.43, \mathrm{p}=0.14\right)$. There was a significant difference between the groups on the post-injury AFQT scores $\left(\chi^{2}=14.44, p=0.002\right)$, and Bonferroni adjusted pairwise comparisons showed vmPFC patients had significantly lower postinjury intelligence scores than $\mathrm{HC}(\mathrm{U}=-35.9, \mathrm{Z}=-3.71, \mathrm{p}=0.001)$ and marginally lower postinjury intelligence scores than the no PFC lesion group $(\mathrm{U}=-23.8, \mathrm{Z}=-2.59, \mathrm{p}=0.058)$, 
although the post-injury AFQT scores for vmPFC patients were within normal limits $(48.15 \pm$ 22.88).

To understand whether there was a relationship between laterality of brain damage and fundamentalism, we selected patients from the vmPFC and dlPFC groups who sustained unilateral lesions. There were 6 patients with exclusively left vmPFC lesions, and 4 patients with exclusively right vmPFC lesions. The data did not support statistically reliable differences in fundamentalism between these two groups $(U=6, Z=-1.28, p=0.20)$. There were 6 patients with exclusively left dlPFC lesions and 18 patients with exclusively right dlPFC lesions and once again the data did not reveal statistically significant differences in fundamentalism between these two groups $(\mathrm{U}=47, \mathrm{Z}=-0.47, \mathrm{p}=0.64)$. These results did not support the hypothesis that differences in laterality of lesion in the PFC is associated with differences in fundamentalism scores.

Finally, to study the relationship between brain tissue damage and fundamentalism, we also performed voxel-based lesion-symptom mapping (VLSM). However, VLSM results were not statistically significant.

\subsection{Mediation analysis}

Both cognitive flexibility $(\beta=-0.25, \mathrm{t}=-2.92, \mathrm{p}=0.004)$ and openness $(\beta=-0.33, \mathrm{t}=-3.85, \mathrm{p}<$ 0.001) are significant predictors of fundamentalism as demonstrated in regression analysis $\left(\mathrm{F}_{(2,109)}=13.74, \mathrm{p}<0.001\right.$, Adjusted $\left.\mathrm{R}^{2}=0.19\right)$. We next explored whether the mediating variable (cognitive flexibility or openness) in our three-variable path model significantly reduced the relationship between the predictor (vmPFC or dlPFC lesion size) and outcome 
(fundamentalism) variables while controlling for lesions in the other PFC region (dlPFC or vmPFC) as a covariate (see Fig. 3).

First, we investigated the relationship between lesion size in the dIPFC or vmPFC and fundamentalism with cognitive flexibility as the mediator. In a simple mediation with dIPFC lesion size entered as the independent variable, cognitive flexibility entered as the mediator, and controlling for vmPFC lesion size as a covariate, we found a significant indirect effect $(b=$ $0.0070, \mathrm{SE}=0.0041,95 \% \mathrm{CI}=[0.0009,0.017])$. In contrast, there is no significant mediation effect of cognitive flexibility on the relationship between vmPFC lesion and fundamentalism, when dIPFC lesion size is controlled for (indirect effect $b=0.0026, \mathrm{SE}=0.0024,95 \% \mathrm{CI}=[-$ 0.0004, 0.0094]). Therefore, a dlPFC lesion influenced fundamentalism through its effect on cognitive flexibility, with vmPFC lesion size taken into account. Larger dIPFC lesion size is associated with decreased cognitive flexibility, and lower cognitive flexibility, in turn, is predictive of greater fundamentalism.

Similarly, we also examined whether lesion size in vmPFC or dIPFC affects fundamentalism through openness. We found that dlPFC lesion influenced fundamentalism, by exerting its effect on openness (indirect effect $\mathrm{b}=0.01, \mathrm{SE}=0.005,95 \% \mathrm{CI}=[0.0024,0.024]$ ), when vmPFC lesion size is controlled for. However, when vmPFC lesion size is entered as the predictor, openness entered as the mediator, and dlPFC lesion size statistically controlled for, we did not find evidence for a significant indirect effect $(b=-0.0018, S E=0.0035,95 \% \mathrm{CI}=[-0.009$, 0.0051]). Thus, dlPFC lesion size also affected fundamentalism indirectly through its effect on openness. 
There were no statistically significant mediation effects supported when percentage of lesion outside PFC was used as the predictor, cognitive flexibility or openness entered as the mediator, and dIPFC and vmPFC lesion size controlled for as covariates (Cognitive flexibility: indirect effect $b=0.0007, \mathrm{SE}=0.0084,95 \% \mathrm{CI}=[-0.018,0.016]$; Openness: indirect effect $\mathrm{b}=0.0022$, $\mathrm{SE}=0.0128,95 \% \mathrm{CI}=[-0.021,0.033])$.

To examine the contribution of these predictors to explaining fundamentalism, we first regressed the fundamentalism scores on dIPFC and vmPFC lesion volume. Taken together, these PFC lesions contribute $3.5 \%$ to the fundamentalism score $\left(\mathrm{F}_{(2,108)}=2.97, \mathrm{p}=0.056\right.$, Adjusted $\mathrm{R}^{2}=$ 0.035). vmPFC lesion size uniquely explains $1.3 \%$ of total variance while dlPFC lesion size uniquely explains $1.7 \%$ of total variance.

After adding openness and cognitive flexibility as predictors, the model explains about $18.5 \%$ of total variance in fundamentalism $\left(\mathrm{F}_{(4,106)}=7.23, \mathrm{p}<0.001\right.$, Adjusted $\left.\mathrm{R}^{2}=0.185\right)$. Cognitive flexibility contributes $4.6 \%$ of unique variance explained, and openness contributes $9.7 \%$ of unique variance. With these factors taken into account, vmPFC explains $1 \%$ of unique variance and dlPFC explains only $0.02 \%$ of unique variance, which is in line with the significant mediation effect of the cognitive measures on fundamentalism.

It has been proposed that Openness consists of at least two components: intellect and aesthetic openness. While aesthetic openness reflects a dimension related to sensory or perceptual information, the intellect component reflects qualities related to abstract or semantic information (DeYoung, 2014). The intellect component of Openness can be measured by the Ideas facet score of the NEO-PI-R, while the aesthetic component can be measured by the Aesthetics facet score (DeYoung, Shamosh, Green, Braver, \& Gray, 2009). The NEO-PI-R facet scores were not 
accessible in Phase 4 of the VHIS, but were available from Phase 3, which was collected about 5 years before Phase 4. The NEO Openness factor scores were significantly correlated between the two phases $($ rho $=0.73, \mathrm{p}<0.0001)$. Therefore, we extracted the Openness facet scores from the Phase 3 NEO-PI-R for further analysis. Mediation analysis supported neither hypothesis. That is, we cannot conclude that either intellectual or aesthetics components independently mediate the relationship between dIPFC lesion and fundamentalism (Intellect: indirect effect $b=0.0069, \mathrm{SE}$ $=0.0056,95 \% \mathrm{CI}=[-0.0004,0.022]$; Aesthetics: indirect effect $\mathrm{b}=0.0008, \mathrm{SE}=0.0036,95 \%$ $\mathrm{CI}=[-0.0050,0.010])$. This analysis may indicate that the mediating effect of openness arises from a combination of both facets. It is also possible that the mediation effect is attributable to a latent variable rather than intellectual or aesthetic openness.

\section{Discussion}

The current study tested the hypothesis that functional processing in PFC regions underpin religious conviction by adjusting cognitive flexibility and openness to accommodate diverse religious views. Using a lesion mapping approach in a large sample of patients with pTBI, we found that participants with vmPFC lesions reported greater fundamentalism. When probing for the cognitive mechanisms underlying the effect of neural damage on fundamentalism, we found it was the extent of dlPFC volume loss that indirectly affected fundamentalist beliefs through its effect on cognitive flexibility and openness.

Our study finds support from a wealth of previous research, including (Asp, et al., 2012; Bulbulia, 2009; Schjoedt, Stodkilde-Jorgensen, Geertz, Lund, \& Roepstorff, 2011), and indicates 
the importance of openness for adapting fundamentalist beliefs, a novel finding. The model developed in the present study improves on Asp, et al. (2012) by describing how general features of cognition support fundamentalism. Our model is also novel because it specifies a path model to test the links between brain, cognitive features and fundamentalism. Here we show that the cognitive mechanisms that underlie fundamentalism can at least partially be attributed to openness processing. Our results also challenge the "false belief tagging" hypothesis. Religious fundamentalism would quickly become maladaptive were it simply false belief — or confabulation, as pointed out in theoretical work by Bulbulia (2009) (for a discussion see Cristofori, Bulbulia, et al., 2015). To reiterate, the present study provides new knowledge about the brain and cognitive bases of belief by linking fundamentalism to general cognitive functions computed in the PFC related to openness, which is, critically, a continuous cognitive process.

Patients with vmPFC lesions scored higher in fundamentalism than patients without PFC lesions, which is consistent with the pivotal role of the vmPFC in social belief representation and maintenance (Krueger \& Grafman, 2012), and with previous lesion studies showing that a vmPFC lesion induces increased fundamentalism (Asp, et al., 2012). Adherence to religious beliefs are highly reinforced and well-rehearsed and can be found across different cultures. Given our research and that of others, it appears likely that diverse religious beliefs are critically represented in the anterior frontal lobe, similar to other forms of complex social knowledge, whereas religious heuristics and simple stereotypic beliefs may be more distributed throughout the posterior frontal and anterior temporal lobes (Forbes \& Grafman, 2010). In the context of a PFC lesion, over-learned heuristics can still be preserved and may become more salient (leading to an increase in professed fundamentalist beliefs), while more diverse, complex and deliberated belief representations become less accessible due to vmPFC damage. In addition, patients with 
lesions to the vmPFC frequently show impairments in social and reward valuation (Mah, Arnold, \& Grafman, 2005; Moretti, Dragone, \& di Pellegrino, 2009), and this might lead to changes in their social judgments. For example, patients with vmPFC lesions are more prone to judge extreme (and potentially fundamentalist) behaviors as more acceptable (Cristofori, Viola, et al., 2015). Our interpretation of the accumulated findings is that fundamentalist religious beliefs arise from the integrated processing and computations in a distributed brain network, with the vmPFC as an essential hub in the circuitry.

Two patients with the lowest fundamentalism scores in the vmPFC and dIPFC groups were close to being outliers in their respective groups, despite not meeting statistical criteria for outliers, and may have skewed the group data. We did not detect a difference between the dlPFC group and the control groups, which may be due to the limited power in the selective lesion groups, which have relatively more focal lesions and smaller sample sizes.

If religious beliefs are partially dependent on correct functioning of the PFC, what is the potential cognitive mechanism underlying the effect of prefrontal damage on religious beliefs? In this study, we tested a model according to which the suppression of cognitive flexibility and openness leads to rigidity in religious beliefs. We found that when vmPFC lesion size is controlled for, greater relative dlPFC lesion damage was associated with greater reductions in cognitive flexibility and openness, and that less cognitive flexibility and openness in turn predicts an increase in fundamentalist beliefs. This finding is in line with the pivotal role of the dlPFC in orchestrating task-switching, and therefore cognitive flexibility (Bunge \& Crone, 2009; Monchi, et al., 2006). 
Evidence suggests that social cognitive processing underpins the categorization of religious experiences (Cristofori, Bulbulia, et al., 2015; Schjoedt, Stdkilde-Jorgensen, Geertz, \& Roepstorff, 2009). Religious experiences are subjective experiences, interpreted within a religious framework and are considered real encounters with God or gods, or real contact with higher-order entities. Importantly, social-functionalist accounts of religion observe that while modulation of social and event processing may regulate religious experiences, it is insufficient for religion to enable social prediction. To predict group-level commitments, religious beliefs must also remain stable over time, and conserved against countervailing evidence. This functional constraint implies that religious belief requires more than religious experience. Put simply, social-functional models predict functionally specific advantages to belief maintenance from the suppression of trait openness and flexible cognitive responses.

A body of other studies has found associations between religious fundamentalism and higherorder cognitive processes. For instance, the meta-analysis by Zuckerman, et al. (2013) analyzing 63 studies found a negative association between intelligence and religiosity and examined several possible explanations. Intelligent individuals may be less likely to conform to a set of religious doctrines; a more analytic thinking style adopted by intelligent individuals has been demonstrated to discourage religious belief (Gervais \& Norenzayan, 2012); and some beneficial facets of religiosity, including compensatory control, self-regulation, self-enhancement, and secure attachment, are also provided by intelligence and thus higher intelligence reduces the need to strictly adhere to fundamentalist religious beliefs and practices. Recent studies have found reduced error-related negativity $(\mathrm{ERN})$ in religious individuals (Inzlicht, McGregor, Hirsh, \& Nash, 2009). Since ERNs are associated with flexible attentional control (Yeung, Botvinick, \& Cohen, 2004), some suggest this decrease in the ERN signature in religious individuals may 
reflect lower cognitive flexibility and increased closed-mindedness (Amodio, Jost, Master, \& Yee, 2007; Lynn, Harvey, \& Nyborg, 2009), although others have argued this observation was due to the palliative effect of religion (Inzlicht, Tullett, \& Good, 2011). Although many studies have demonstrated negative correlation between cognitive flexibility and religiousness, other research showed the opposite trend. A recent study by Neyrinck, Vansteenkiste, Lens, Duriez, and Hutsebaut (2006) found that individuals actively involved in religious practices for its perceived personal significance showed more cognitive flexibility and open mindedness towards religious beliefs.

Several study limitations should be apparent in light of our rare participant sample. Our participants were all male Vietnam combat veterans. Only CT scans could be used to identify lesion location and size given the presence of metal within the brain due to low velocity shrapnel wounds. Further studies using larger and more diverse samples, including female and nonmilitary samples, are necessary to confirm that our conclusions are applicable to healthy individuals or other clinical populations (e.g., epilepsy patients).

Although it was once thought that religious belief has a special status in the human brain, the evidence suggests that religious beliefs emerge in conjunction with other beliefs, such as moral, political and legal beliefs (van Elk, 2015). Previous research comparing religious and nonreligious beliefs suggested that beliefs in both categories of propositions similarly engage the vmPFC, but processing of religious and nonreligious stimuli differentially recruits additional regions in the frontal, parietal and temporal lobes (Harris, et al., 2009). The present study investigates the effect of PFC lesions on religious fundamentalism via cognitive flexibility and openness. One future direction would be to understand whether the brain and cognitive bases of 
religious fundamentalism beliefs differ from other forms of fundamentalism such as political fundamentalism.

It is important to highlight that the religious fundamentalism construct could have a high number of covariates and the effect sizes we report are modest as is often the case for personality and complex behaviors. In addition, the general quality of life affected by post-injury cognitive function could interact with many of the questions from the fundamentalism scale. These are among the interesting challenges ahead for researchers who take up our method of integrating self-report data with functional neuroimaging.

Cognitive flexibility and openness are by no means the sole predictors of religious fundamentalism. We found that PFC lesions along with cognitive flexibility and openness explain less than $20 \%$ of the variation in fundamentalism scores. Therefore, these factors are only a few out of a number of other factors that play a role in modulating adherence of religious beliefs. Other key factors contributing to the formation of fundamentalist beliefs can range from genetic predispositions related to cognition to a host of peer and other social influences.

Our results indicated that regions in the PFC, including the dlPFC and vmPFC, significantly contribute to the formation of fundamentalist beliefs and that there was a functional relationship between fundamentalism, openness and cognitive flexibility. Fundamentalist thinking, therefore, eschews deliberation in favor of rigid conviction. Social-functional theories argue that belief maintenance is vital for social prediction. We note that if religious beliefs were prone to change over the course of experience due to deliberative or other processes, they could not function as predictors of social response, that is, as ideological commitments. That is one reason why we 
suspected that neural networks associated with openness and cognitive flexibility would affect the commitment to religious convictions, independently of social event processing.

Our study uses evidence from participants with selective brain damage to clarify the relationship between cognitive flexibility, trait openness and the maintenance of religious conviction. It is important to investigate the specific functional role of cognitive rigidity in the maintenance and production of religious beliefs, because there is confusion about the relationship between flexibility and religious beliefs (Inzlicht, et al., 2011; Zuckerman, et al., 2013). We do not propose that religious people are generally cognitively inflexible. Religious belief is the product of multiple and coordinated functional activities across the brain. Our study indicates that one of the functions that support the maintenance of religious conviction is the suppression of belief revision. A key scientific question ahead is how social and ecological responses interact and remain flexible in religious people, and may in some cases become augmented, while religious belief revision is selectively suppressed. Additionally, the specific links between religious doctrine and social prediction and adaptiveness remain unclear, and merit future study.

The present findings contribute a piece to what is becoming an increasingly complex depiction of religious beliefs that will occupy investigators for many decades because of its historically key contribution to human social behavior. In summary, we found that adherence to fundamentalist religious doctrine is partly mediated by diminished flexible conceptual thinking and reduced openness and that the key cortical region supporting the representation of diverse religious belief as well as flexible conceptual thinking is the dlPFC.

\section{Acknowledgements}


We are grateful to our Vietnam veterans for their dedicated participation in the study. We thank

J. Solomon for his assistance with ABLe, as well as V. Raymont, S. Bonifant, B. Cheon, C. Ngo, A. Greathouse, K. Reding, and G. Tasick for testing and evaluating participants. We would also like to thank the National Naval Medical Center and the National Institute of Neurological Disorders and Stroke for providing support and facilities. The views expressed in this article are those of the authors and do not reflect the official policy or position of the Department of the Navy, the Department of Defense, or the U.S. Government.

\section{References}

Adelstein, J. S., Shehzad, Z., Mennes, M., DeYoung, C. G., Zuo, X. N., Kelly, C., Margulies, D. S., Bloomfield, A., Gray, J. R., Castellanos, F. X., \& Milham, M. P. (2011). Personality Is Reflected in the Brain's Intrinsic Functional Architecture. PLoS One, 6.

AFQT-7A. (1960). Department of Defense Form 1293, March 1.

Altemeyer, B., \& Hunsberger, B. (1992). Authoritarianism, religious fundamentalism, quest, and prejudice. International Journal for the Psychology of Religion, 2, 113-133.

Altemeyer, B., \& Hunsberger, B. (2005). Fundamentalism and authoritarianism. New York, NY: Guilford.

Alvarez, J. A., \& Emory, E. (2006). Executive function and the frontal lobes: a meta-analytic review. Neuropsychol Rev, 16, 17-42. 
Amodio, D. M., Jost, J. T., Master, S. L., \& Yee, C. M. (2007). Neurocognitive correlates of liberalism and conservatism. Nat Neurosci, 10, 1246-1247.

Asp, E., Ramchandran, K., \& Tranel, D. (2012). Authoritarianism, religious fundamentalism, and the human prefrontal cortex. Neuropsychology, 26, 414-421.

Bader, C., Dougherty, K., Froese, P., Johnson, B., Mencken, F. C., Park, J. Z., \& Stark, R. (2006). American Piety in the 21st Century: New Insights to the Depth and Complexity of Religion in the US. Baylor Institute for Studies of Religion, Baylor University, Waco, Texas.

Barbey, A. K., Colom, R., \& Grafman, J. (2013). Architecture of cognitive flexibility revealed by lesion mapping. Neuroimage, 82, 547-554.

Batson, C. D., \& Schoenrade, P. A. (1991a). Measuring religion as quest: 1) Validity concerns. Journal for the Scientific Study of Religion, 416-429.

Batson, C. D., \& Schoenrade, P. A. (1991b). Measuring religion as quest: 2) Reliability concerns. Journal for the Scientific Study of Religion, 430-447.

Brandt, M. J., \& Reyna, C. (2010). The Role of Prejudice and the Need for Closure in Religious Fundamentalism. Personality and Social Psychology Bulletin, 36, 715-725.

Bulbulia, J. (2009). Religiosity as mental time-travel. In The believing primate (pp. 44-75).

Bulbulia, J., \& Schjoedt, U. (2012). The neural basis of religious belief. In F. Krueger \& J. Grafman (Eds.), The Neural Basis of Human Belief Systems (pp. 169-190): Psychology Press.

Bulbulia, J., \& Sosis, R. (2009a). Belief as ideology. Behavior and the Brain Sciences, 32, 515-516.

Bulbulia, J., \& Sosis, R. (2009b). Ideology as cooperative affordance. Behavioral and Brain Sciences, 32, $515-+$.

Bunge, S. A., \& Crone, E. A. (2009). Neural correlates of the development of cognitive control. Neuroimaging in Developmental Clinical Neuroscience, 22-37.

Calogero, R. M., Bardi, A., \& Sutton, R. M. (2009). A need basis for values: Associations between the need for cognitive closure and value priorities. Personality and Individual Differences, 46, 154159. 
Canas, J. J., Quesada, J. F., Antoli, A., \& Fajardo, I. (2003). Cognitive flexibility and adaptability to environmental changes in dynamic complex problem-solving tasks. Ergonomics, 46, 482-501.

Chapman, B., Duberstein, P., Tindle, H. A., Sink, K. M., Robbins, J., Tancredi, D. J., Franks, P., \& Inv, G. E. M. S. (2012). Personality Predicts Cognitive Function Over 7 Years in Older Persons. American Journal of Geriatric Psychiatry, 20, 612-621.

Connelly, B. S., Ones, D. S., Davies, S. E., \& Birkland, A. (2014). Opening Up Openness: A Theoretical Sort Following Critical Incidents Methodology and a Meta-Analytic Investigation of the Trait Family Measures. Journal of Personality Assessment, 96, 17-28.

Costa, P. T., \& McCrae, R. R. (1992). NEO PI-R professional manual. Odessa, FL: Psychological Assessment Resources, Inc.

Cristofori, I., Bulbulia, J., Shaver, J. H., Wilson, M., Krueger, F., \& Grafman, J. (2015). Neural correlates of mystical experience. Neuropsychologia, 80, 212-220.

Cristofori, I., \& Grafman, J. (in press). Neural Underpinnings of the Human Belief System. In H. F. Angel, L. Oviedo, R. F. Paloutzian, A. L. C. Runehov \& R. J. Seitz (Eds.), Processes of Believing: The Acquisition, Maintenance, and Change in Creditions (Vol. 1).

Cristofori, I., Viola, V., Chau, A., Zhong, W., Krueger, F., Zamboni, G., \& Grafman, J. (2015). The neural bases for devaluing radical political statements revealed by penetrating traumatic brain injury. Soc Cogn Affect Neurosci, 10, 1038-1044.

Delis, D. C., Kaplan, E., \& Kramer, J. H. (2001). The Delis Kaplan Executive Function System: Examiner's manual. San Antonio, TX: The Psychological Corporation.

DeYoung, C. G. (2014). Openness/Intellect: A dimension of personality reflecting cognitive exploration. . In M. L. Cooper \& R. J. Larsen (Eds.), APA handbook of personality and social psychology: Personality processes and individual differences (Vol. 4, pp. 369 - 399). Washington, DC: American Psychological Association. 
DeYoung, C. G., Cicchetti, D., Rogosch, F. A., Gray, J. R., Eastman, M., \& Grigorenko, E. L. (2011). Sources of cognitive exploration: Genetic variation in the prefrontal dopamine system predicts Openness/Intellect. Journal of Research in Personality, 45, 364-371.

DeYoung, C. G., Peterson, J. B., \& Higgins, D. M. (2005). Sources of Openness/Intellect: Cognitive and neuropsychological correlates of the fifth factor of personality. Journal of Personality, 73, 825858.

DeYoung, C. G., Shamosh, N. A., Green, A. E., Braver, T. S., \& Gray, J. R. (2009). Intellect as distinct from Openness: differences revealed by fMRI of working memory. J Pers Soc Psychol, 97, 883892.

Duckitt, J. (2001). A dual-process cognitive-motivational theory of ideology and prejudice. . In M. P. Zanna (Ed.), Advances in experimental social psychology (Vol. 33, pp. 41-113). New York: Academic Press.

Forbes, C. E., \& Grafman, J. (2010). The role of the human prefrontal cortex in social cognition and moral judgment. Annu Rev Neurosci, 33, 299-324.

Foster, K. R., \& Kokko, H. (2009). The evolution of superstitious and superstition-like behaviour. Proceedings of the Royal Society B-Biological Sciences, 276, 31-37.

Gervais, W. M., \& Norenzayan, A. (2012). Analytic Thinking Promotes Religious Disbelief. Science, $336,493-496$.

Ginges, J., Hansen, I., \& Norenzayan, A. (2009). Religion and support for suicide attacks. Psychol Sci, $20,224-230$.

Gozzi, M., Raymont, V., Solomon, J., Koenigs, M., \& Grafman, J. (2009). Dissociable effects of prefrontal and anterior temporal cortical lesions on stereotypical gender attitudes. Neuropsychologia, 47, 2125-2132.

Guthrie, S. (1993). Faces in the Clouds: A New Theory of Religion. . New York: Oxford University Press. 
Harris, S., Kaplan, J. T., Curiel, A., Bookheimer, S. Y., Iacoboni, M., \& Cohen, M. S. (2009). The Neural Correlates of Religious and Nonreligious Belief. PLoS One, 4.

Hayes, A. F. (2013). Introduction to mediation, moderation, and conditional process analysis. New York: The Guilford Press.

Hunsberger, B., \& Jackson, L. M. (2005). Religion, meaning, and prejudice. Journal of Social Issues, 61, 807-826.

Inzlicht, M., McGregor, I., Hirsh, J. B., \& Nash, K. (2009). Neural Markers of Religious Conviction. Psychol Sci, 20, 385-392.

Inzlicht, M., Tullett, A. M., \& Good, M. (2011). The need to believe: a neuroscience account of religion as a motivated process. Religion, Brain \& Behavior, 1, 192-212.

Jost, J. T., Glaser, J., Kruglanski, A. W., \& Sulloway, F. J. (2003). Political conservatism as motivated social cognition. Psychol Bull, 129, 339-375.

Kay, A. C., Gaucher, D., Napier, J. L., Callan, M. J., \& Laurin, K. (2008). God and the government: Test a compensatory control mechanism for the support of external systems. Journal of Personality and Social Psychology, 95, 18-35.

Kim, C., Johnson, N. F., Cilles, S. E., \& Gold, B. T. (2011). Common and Distinct Mechanisms of Cognitive Flexibility in Prefrontal Cortex. Journal of Neuroscience, 31, 4771-4779.

Krueger, F., \& Grafman, J. (2012). I believe to my soul. In F. Krueger \& J. Grafman (Eds.), The Neural Basis of Human Beliefs System (pp. 225-236). New York, NY: Psychological Press.

Krueger, F., Pardini, M., Huey, E. D., Raymont, V., Solomon, J., Lipsky, R. H., Hodgkinson, C. A., Goldman, D., \& Grafman, J. (2011). The role of the Met66 brain-derived neurotrophic factor allele in the recovery of executive functioning after combat-related traumatic brain injury. $\mathrm{J}$ Neurosci, 31, 598-606.

Kruglanski, A. W., \& Webster, D. M. (1996). Motivated closing of the mind: "Seizing" and "Freezing". Psychological Review, 103, 263-283. 
Kunisato, Y., Okamoto, Y., Okada, G., Aoyama, S., Nishiyama, Y., Onoda, K., \& Yamawaki, S. (2011). Personality traits and the amplitude of spontaneous low-frequency oscillations during resting state. Neuroscience Letters, 492, 109-113.

Lewis, G. J., Ritchie, S. J., \& Bates, T. C. (2011). The relationship between intelligence and multiple domains of religious belief: Evidence from a large adult US sample. Intelligence, 39, 468-472.

Lynn, R., Harvey, J., \& Nyborg, H. (2009). Average intelligence predicts atheism rates across 137 nations. Intelligence, 37, 11-15.

Mah, L. W., Arnold, M. C., \& Grafman, J. (2005). Deficits in social knowledge following damage to ventromedial prefrontal cortex. J Neuropsychiatry Clin Neurosci, 17, 66-74.

Mayr, U., \& Keele, S. W. (2000). Changing internal constraints on action: the role of backward inhibition. J Exp Psychol Gen, 129, 4-26.

McCrae, R. R. (1996). Social consequences of experiential openness. Psychol Bull, 120, 323-337.

McCullough, M. E., \& Willoughby, B. L. (2009). Religion, self-regulation, and self-control: Associations, explanations, and implications. Psychol Bull, 135, 69-93.

McNeil, M. M., \& Prescott, T. E. (1994). Revised Token Test. Los Angeles, CA.

Monchi, O., Petrides, M., Strafella, A. P., Worsley, K. J., \& Doyon, J. (2006). Functional role of the basal ganglia in the planning and execution of actions. Ann Neurol, 59, 257-264.

Monsell, S. (2003). Task switching. Trends Cogn Sci, 7, 134-140.

Moretti, L., Dragone, D., \& di Pellegrino, G. (2009). Reward and social valuation deficits following ventromedial prefrontal damage. J Cogn Neurosci, 21, 128-140.

Neyrinck, B., Vansteenkiste, M., Lens, W., Duriez, B., \& Hutsebaut, D. (2006). Cognitive, affective and behavioral correlates of internalization of regulations for religious activities. Motivation and Emotion, 30, 323-334.

Norenzayan, A., Gervais, W. M., \& Trzesniewski, K. H. (2012). Mentalizing Deficits Constrain Belief in a Personal God. PLoS One, 7. 
Passamonti, L., Terracciano, A., Riccelli, R., Donzuso, G., Cerasa, A., Vaccaro, M. G., Novellino, F., Fera, F., \& Quattrone, A. (2015). Increased functional connectivity within mesocortical networks in open people. Neuroimage, 104, 301-309.

Ravizza, S. M., \& Carter, C. S. (2008). Shifting set about task switching: behavioral and neural evidence for distinct forms of cognitive flexibility. Neuropsychologia, 46, 2924-2935.

Raymont, V., Salazar, A. M., Krueger, F., \& Grafman, J. (2011). "Studying injured minds" - the Vietnam head injury study and 40 years of brain injury research. Front Neurol, 2, 15.

Saroglou, V. (2002). Beyond dogmatism: The need for closure as related to religion. Mental Health, Religion \& Culture, 5, 183-194.

Scheufele, D. A., Corley, E. A., Shih, T. J., Dalrymple, K. E., \& Ho, S. S. (2009). Religious beliefs and public attitudes toward nanotechnology in Europe and the United States. Nat Nanotechnol, 4, 9194.

Schjoedt, U., Stdkilde-Jorgensen, H., Geertz, A. W., \& Roepstorff, A. (2009). Highly religious participants recruit areas of social cognition in personal prayer. Soc Cogn Affect Neurosci, 4, 199-207.

Schjoedt, U., Stodkilde-Jorgensen, H., Geertz, A. W., Lund, T. E., \& Roepstorff, A. (2011). The power of charisma-perceived charisma inhibits the frontal executive network of believers in intercessory prayer. Soc Cogn Affect Neurosci, 6, 119-127.

Schretlen, D. J., van der Hulst, E. J., Pearlson, G. D., \& Gordon, B. (2010). A neuropsychological study of personality: Trait openness in relation to intelligence, fluency, and executive functioning. Journal of Clinical and Experimental Neuropsychology, 32, 1068-1073.

Sibley, C. G., Robertson, A., \& Wilson, M. S. (2006). Social dominance orientation and right-wing authoritarianism: Additive and interactive effects. Political Psychology, 27, 755-768.

Toepper, M., Gebhardt, H., Beblo, T., Thomas, C., Driessen, M., Bischoff, M., Blecker, C. R., Vaitl, D., \& Sammer, G. (2010). Functional correlates of distractor suppression during spatial working memory encoding. Neuroscience, 165, 1244-1253. 
Tzourio-Mazoyer, N., Landeau, B., Papathanassiou, D., Crivello, F., Etard, O., Delcroix, N., Mazoyer, B., \& Joliot, M. (2002). Automated anatomical labeling of activations in SPM using a macroscopic anatomical parcellation of the MNI MRI single-subject brain. Neuroimage, 15, 273-289.

van Elk, M. (2015). Perceptual Biases in Relation to Paranormal and Conspiracy Beliefs. PLoS One, 10, e0130422.

Vecchione, M., \& Caprara, G. V. (2009). Personality determinants of political participation: The contribution of traits and self-efficacy beliefs. Personality and Individual Differences, 46, 487492.

von Stumm, S. (2013). Investment Traits and Intelligence in Adulthood Assessment and Associations. Journal of Individual Differences, 34, 82-89.

Whiting, D. L., Deane, F. P., Simpson, G. K., McLeod, H. J., \& Ciarrochi, J. (2015). Cognitive and psychological flexibility after a traumatic brain injury and the implications for treatment in acceptance-based therapies: A conceptual review. Neuropsychol Rehabil, 1-37.

Willard, A. K., \& Norenzayan, A. (2013). Cognitive biases explain religious belief, paranormal belief, and belief in life's purpose. Cognition, 129, 379-391.

Yeung, N., Botvinick, M. M., \& Cohen, J. D. (2004). The neural basis of error detection: Conflict monitoring and the error-related negativity. Psychological Review, 111, 931-959.

Zuckerman, M., Silberman, J., \& Hall, J. A. (2013). The Relation Between Intelligence and Religiosity: A Meta-Analysis and Some Proposed Explanations. Personality and Social Psychology Review, 17, 325-354. 


\section{Tables}

Table 1. Demographic and neuropsychological measures for patients with penetrating traumatic brain injury (pTBI; $\mathrm{N}=119)$ and healthy controls ( $\mathrm{HC} ; \mathrm{N}=30)$.

\begin{tabular}{|l|l|l|l|}
\hline & $\mathrm{pTBI}$ & $\mathrm{HC}$ & Statistics \\
\hline Age & $63.42 \pm 2.94$ & $63.13 \pm 3.50$ & $\mathrm{U}=1623, \mathrm{Z}=-0.71, \mathrm{p}=0.48$ \\
\hline Education & $14.63 \pm 2.24$ & $15.13 \pm 2.21$ & $\mathrm{U}=1560, \mathrm{Z}=-1.02, \mathrm{p}=0.31$ \\
\hline Preinjury AFQT & $65.71 \pm 23.33$ & $71.20 \pm 17.39$ & $\mathrm{U}=932, \mathrm{Z}=-0.85, \mathrm{p}=0.39$ \\
\hline Postinjury AFQT & $57.02 \pm 25.48$ & $73.17 \pm 19.94$ & $\mathrm{U}=1027, \mathrm{Z}=-3.20, \mathrm{p}=0.001$ \\
\hline Token Test & $98.07 \pm 2.64$ & $98.43 \pm 1.92$ & $\mathrm{U}=1662, \mathrm{Z}=-0.32, \mathrm{p}=0.75$ \\
\hline D-KEFS Sorting & $21.01 \pm 5.82$ & $24.54 \pm 5.42$ & $\mathrm{U}=1012, \mathrm{Z}=-2.95, \mathrm{p}=0.003$ \\
\hline Fundamentalism & $0.038 \pm 0.91$ & $-0.16 \pm 1.08$ & $\mathrm{U}=1594, \mathrm{Z}=-0.90, \mathrm{p}=0.37$ \\
\hline
\end{tabular}

AFQT, Armed Forces Qualification Test (percentile score); D-KEFS, Delis Kaplan Executive

Function System. Normal ranges for tests: AFQT, 31 - 99 percentile; TT, 50 - 100; D-KEFS Sorting, $14-38$. 


\section{Figure Legends}

A) vmPFC group $(N=24)$

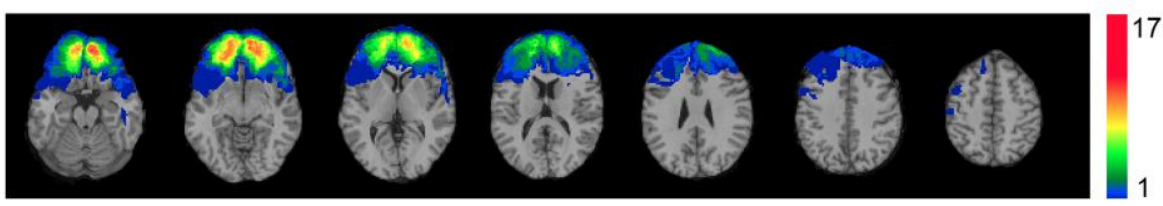

B) $\underset{\text { dIPFC group }}{(\mathrm{N}=31)}$
?

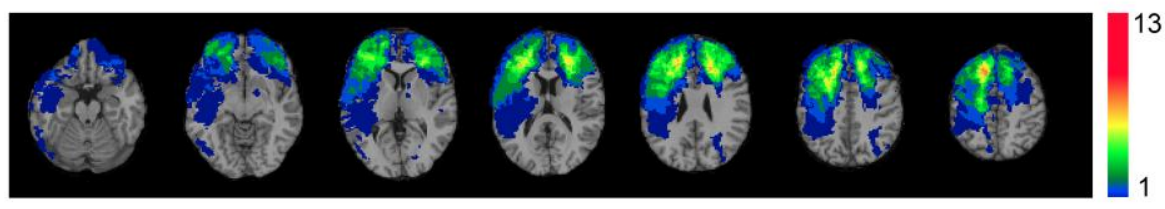

C) no PFC group $(\mathrm{N}=37)$

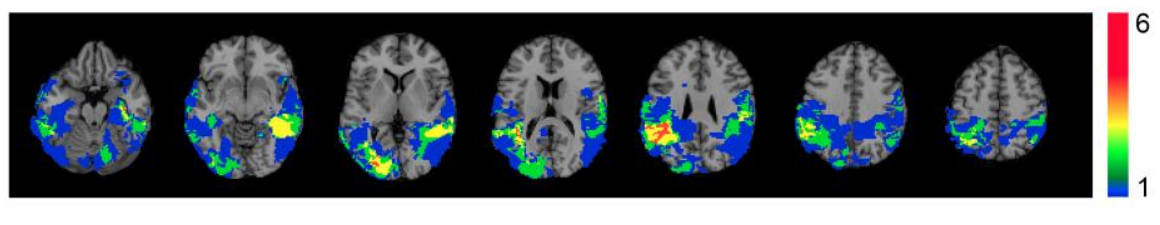

$$
Z=-20 \quad Z=-8 \quad Z=4 \quad Z=16 \quad Z=28 \quad Z=40 \quad Z=52
$$

Figure 1. Lesion overlay maps of pTBI patients in the focal lesion groups (vmPFC, dlPFC, no PFC). Color indicates the number of patients with overlapping lesion at each voxel. Red indicates highest lesion overlap density and blue indicates lowest lesion overlap density. Images are in radiological convention: right hemisphere is on the reader's left. 


\section{Fundamentalism score by lesion groups}

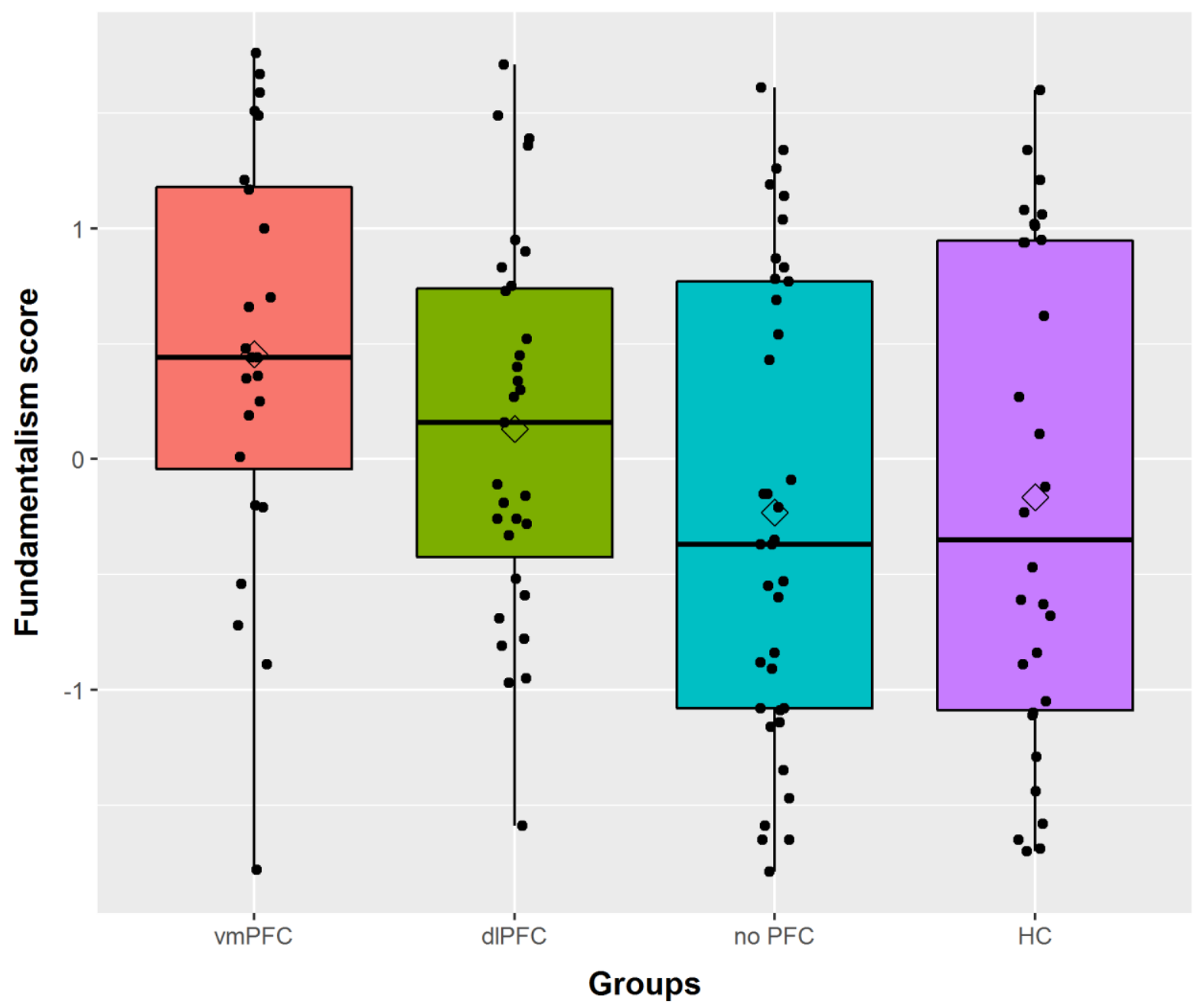

Figure 2. Fundamentalism scores of the patient and healthy control groups. Patients with lesion predominantly in the vmPFC have higher fundamentalism scores than patients without vmPFC or dlPFC lesions. The diamond indicates the value of the group mean. 
A)

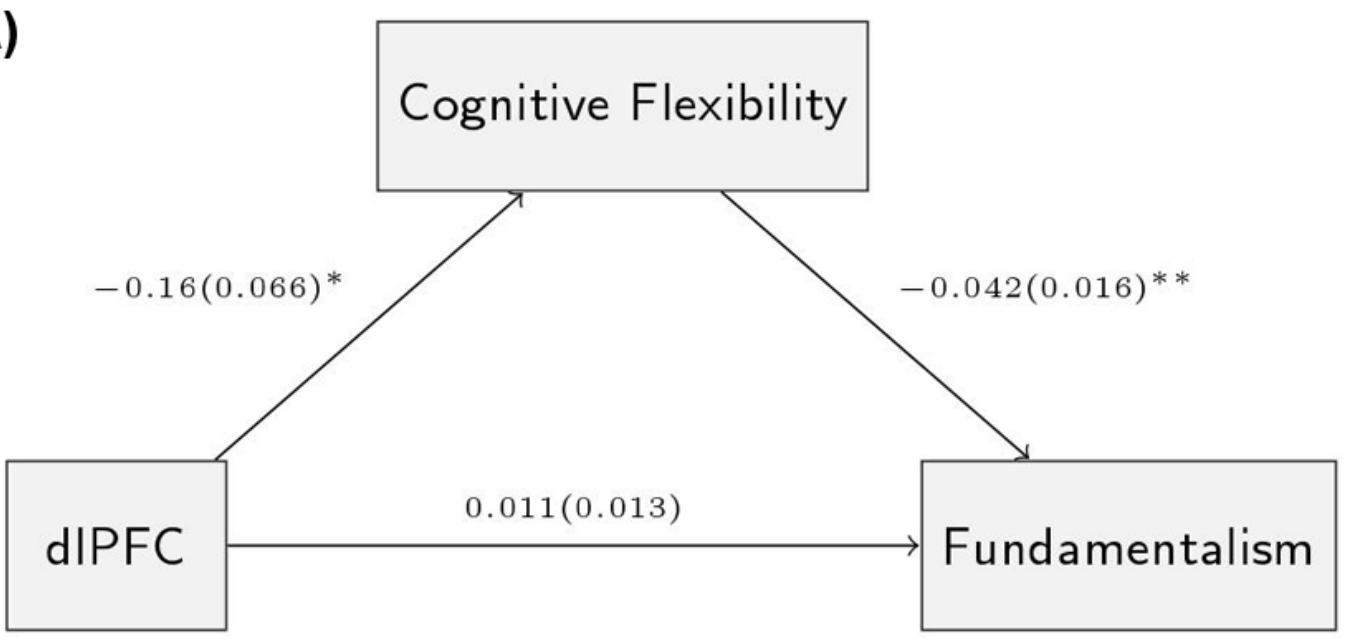

B)

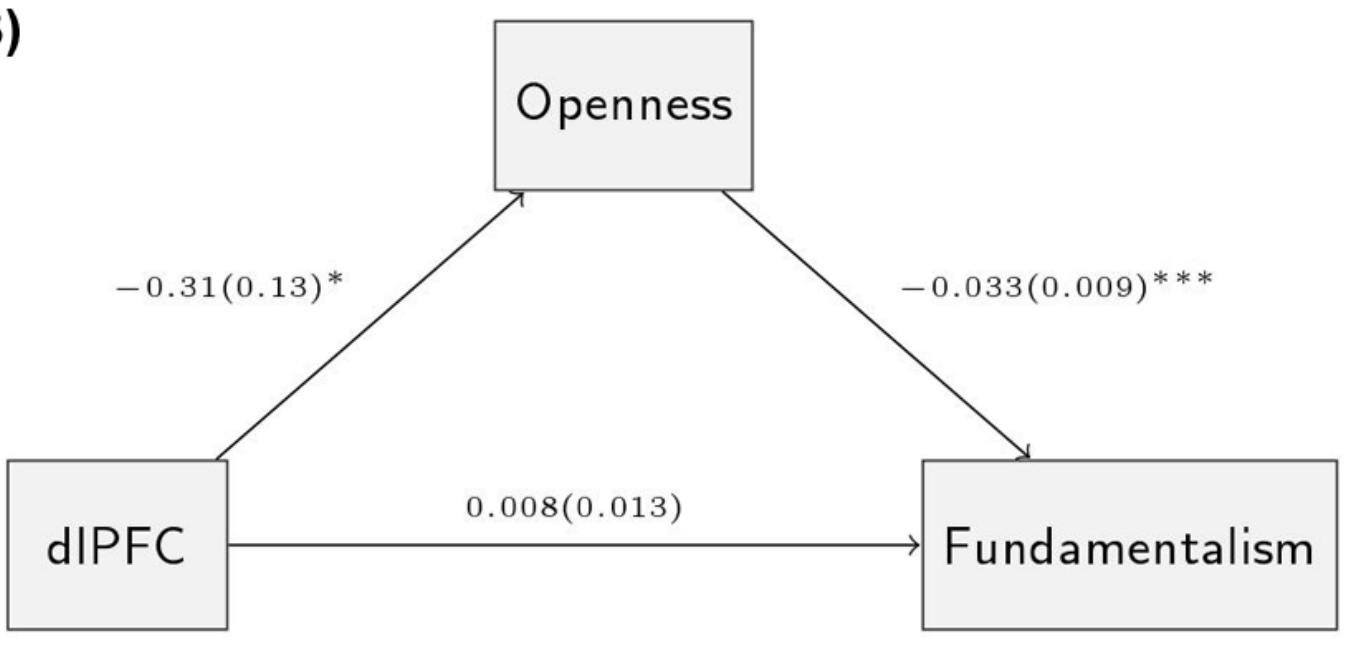

Figure 3. Results of the mediation analyses. The mediation analyses test the effect of A) Cognitive flexibility; and B) Openness on the relationship between dlPFC lesion and fundamentalism score while controlling for vmPFC lesion as a covariate. The diagrams show the coefficients \pm SE of the path model significant at $* * * \mathrm{p}<0.001, * * \mathrm{p}<0.01$ and $* \mathrm{p}<0.05$. 